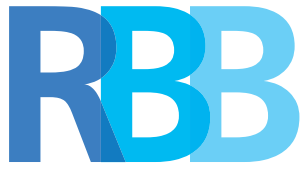

Revista Brasileira de Bioética

Caroline Filla Rosaneli

Escola de Ciência da Vida, Programa de Pós-Graduação em Bioética da PUCPR

Curitiba, Paraná, Brasil caroline.rosaneli@gmail.com

Anor Sganzerla

Escola de Ciência da Vida. Programa de Pós-Graduação em Bioética da PUCPR

Curitiba, Paraná, Brasil anor.sganzela@gmail.com

Jaqueline Stramantino

Escola de Ciência da Vida, PUCPR

Curitiba, Paraná, Brasil jaqstra@hotmail.com

Lyégie Lys R. Barancelli

Escola de Ciência da Vida, PUCPR

Curitiba, Paraná, Brasil lyegie.lys@gmail.com

\section{A fome e o sistema alimentar: a violação da dignidade humana}

Hunger and food system: a violation of human dignity

Resumo: Este artigo tem por objetivo analisar que a questão da fome e da desigual distribuição de alimentos não está diretamente ligada à diminuição da produção dos mesmos, mas sim às escolhas políticas e éticas. Essas opções, por sua vez, por não serem feitas à luz de uma política da equidade, têm impactado fortemente na dignidade da pessoa humana, na medida em que muitos são os indivíduos que não possuem o direito humano à alimentação sendo respeitado. Trata-se de um ensaio reflexivo teórico acerca dos temas fome, produção e desperdício de alimentos, ética, dignidade e liberdade. Para que esse cenário possa ser modificado local e globalmente, faz-se urgente uma nova política, livre do domínio dos interesses econômicos, e orientada por uma ética da solidariedade, da compaixão, da justiça, a fim de que possa assegurar a todas as pessoas o direito humano a alimentação e, consequentemente, a garantia da dignidade humana.

Palavras-chave: fome; dignidade; alimento; bioética; direito humano.

\begin{abstract}
This article aims to demonstrate that the issue of hunger and unequal distribution of food is not directly linked to the decreased production of food, but to political and ethical choices, as food distribution turns not to be made in the light of a policy of equity, and this strongly impacts on the dignity of the human person, to the extent that many individuals who do not have their human right to food respected. This is a theoretical reflective essay about hunger issues, production and food waste, ethics, dignity and freedom. For this scenario to be modified locally and globally, it is urgent a new policy, free from economic interests and guided by an ethics of solidarity, compassion, justice, that ensures that all people have their human right to food and thus the guarantee of human dignity observed.
\end{abstract}

Keywords: hunger; dignity; food; bioethics; human right. 


\section{Introdução}

E stima-se que quase um bilhão de pessoas anualmente em todo o mundo sofra com a fome crônica; destes, 14 milhões seriam brasileiros (FAO, 2014). No Brasil esse número, por sua vez, quando associado à insegurança alimentar, pode chegar a 39,5 milhões de habitantes que vivem em situação de vulnerabilidade em relação à alimentação (Vicino, 2006; Ziegler, 2012).

Esses números ganham ainda mais dramaticidade quando se tem conhecimento de que o desperdício de alimentos no mundo, ao logo de toda a cadeia produtiva, ou seja, da pré-colheita e colheita, passando pelo transporte, armazenamento, até chegar à mesa do consumidor, chega a 30\% do total dos alimentos produzidos (Brasil, 2006; IHU, 2014). No Brasil, a soma total diária desse desperdício é de cerca de 40 mil toneladas de alimentos. Esses números indicam que com o total de alimentos desperdiçados seria possível alimentar diariamente cerca de 19 milhões de pessoas (Goulart, 2008; Soares, 2014).

Se o desperdício de alimentos representa um problema de repercussões na esfera política, econômica, cultural e estrutural, o problema da má distribuição de alimentos tem consequências ainda mais maléficas, na medida em que a desigual distribuição de alimentos ocorre a partir de interesses do mundo capitalista. Trata-se, portanto, de uma questão com consequências na esfera da ética, pois a distribuição ocorre por critérios injustos, e também do mundo da bioética, porque a injusta distribuição viola a dignidade humana de milhões de pessoas (Pessini, Garrafa, 2003). Embora nas últimas décadas tenhamos tido um acréscimo na produção de alimentos, a lógica da distribuição não contribuiu para diminuir o número de pessoas sem acesso ao alimento diário (Machado, Oliveira, Mendes, 2016).

Esses dados indicam que o Direito humano à alimentação adequada (DHAA) e a Segurança alimentar e nutricional (SAN) estão longe de serem atingidos pelo nosso atual modelo de distribuição de alimentos. Afirma o Pacto internacional sobre os direitos econômicos, sociais e culturais (PIDESC) que "o direito à alimentação satisfatória se torna efetivo quando cada homem, mulher e criança, sozinho ou em coletivo, têm alcance físico e econômico a todo tempo à alimentação adequada ou aos meios para sua conquista" - Art. 11, § 1 (Brasil, 1992).

O mesmo Pacto acrescenta em outros parágrafos que "o direito de cada qual a um padrão de vida adequado para si mesmo e sua família, incluindo alimentação adequada (...) e ao melhoramento contínuo de suas condições de vida" - Art. 11, § 1, bem como "o direito fundamental de cada qual a estar livre da fome" - Art. 11, \& 2 (Brasil, 1992) é uma exigência humana e que deve ser atendida. 0 acesso a alimentação para acontecer de forma justa deve ocorrer sem discriminação de origem cultural, econômica ou social, de etnia, gênero, idioma, religião, opção política ou de outra natureza (Belik, Cunha, Costa, 2012). É a partir dessa vulnerabilidade, que a SAN e o DHAA devem concentrar esforços e 
estratégias em vista de superar tal realidade (Abrandh, 2010).

Embora em nossa vida diária estejamos acostumados a ouvir e a usar expressões como a "lógica do mercado" ou mesmo a "economia de mercado", usar do alimento como um produto de mercado, comercializado pela lógica da oferta e da procura, faz com que aqueles que já não têm acesso ao alimento fiquem ainda mais distantes. Nessa lógica do capital, estocar alimentos para que tenham um melhor preço, não representaria um problema do universo moral, mas apenas uma estratégia de mercado. Essa lógica faz com que os grandes grupos globais do comércio mundial de alimentos alcancem resultados econômicos cada vez mais vantajosos. Esse descompasso, no entanto, é justificado como resultado natural de uma economia global. Essa lógica privada do capital, que fez com que o alimento também se tornasse uma mercadoria, acentuou ainda mais as desigualdades econômicas, as patologias sociais (Machado, Oliveira, Mendes, 2016), e o desrespeito à dignidade humana.

Diante desse cenário de desperdício de alimento, e principalmente da sua má distribuição, que tem gerado a fome de milhões de pessoas todos os dias, este estudo busca refletir sobre a violação da dignidade humana frente à fome, o que determina em primeira instância, uma violação dos princípios fundamentais de justiça, dos direitos humanos e das capacidades humanas. Aliada a isto, existe a influência de um perverso sistema alimentar que perpetua a fome na indigesta relação sobre a distribuição de alimentos.

Trata-se de um ensaio reflexivo teórico acerca dos temas fome, produção e desperdício de alimentos, ética, dignidade e liberdade. A elaboração deste estudo não envolveu um método empírico tipicamente quanti ou qualitativo, mas seguiu as orientações sobre a definição de Pesquisa Teórica (Demo, 2000) que "permite reconstruir teoria, conceitos, ideias, ideologias, polêmicas, tendo em vista, em termos imediatos, aprimorar fundamentos teóricos" (p.20). Com isso, estão postas perspectivas para identificar atores responsáveis por este impacto na vida com consequências locais e globais na busca de desenvolvimento de estratégias e recursos para ações de proteção e dignidade humana.

\section{Fome, pobreza e o desperdício de alimentos}

A questão da fome está relacionada com a pobreza porque as condições de desigualdade que favorecem a pobreza acarretam a fome (Valente, 2003). Essa afirmação é confirmada por outros autores (Santos, Arcoverde, 2011) que afirmam: "em sentido geral, ser pobre é não ter o atendimento das necessidades biológicas, é não ter condições mínimas de habitação, vestuário, entre outros recursos. É o não acesso aos bens e serviços necessários à existência humana" (p.3). Outras vezes os alimentos estão disponíveis, no entanto, a falta de recursos impede de se ter seu acesso (Brasil, 2014; Rosaneli, Ribeiro, Assis, 
Silva et al., 2015).

Nesse sentido:

a condição de pobreza e a vivência da fome não permitem ao ser humano senão o contato com um padrão de consumo alimentar de natureza insuficiente e inadequada. O ato de comer é mais do que uma ação com repercussões biológicas, é também uma importante expressão de linguagem, um ato social impregnado de simbolismos. Assim, a escolha do alimento reflete um uso social, que tem um aspecto simbólico (Albuquerque, 2009, p.901).

Por isso, a bioética da proteção tem papel fundamental sobre esse público, pois ela assegura que o Estado reconheça sua obrigação de cuidar dos vulneráveis para atender suas necessidades, sejam elas, naturais, culturais, socioeconômicas ou ambientais (Schramm, 2008). A vulnerabilidade, desse modo, não se reduz a algo intrínseco, pois todos os seres humanos podem ser atingidos pela vulnerabilidade circunstancial. Desta forma, a etapa crucial consiste na potencialização e proteção do elemento vulnerável.

A Declaração universal sobre bioética e direitos humanos (DUBDH), descreve que devemos buscar a "igualdade fundamental de todos os seres humanos na sua dignidade e em seus direitos [...] bem como tratá-los de forma justa e equitativa" (ONU, 2005, p.7). A equidade está vinculada à ética, à escolha de valores, portanto, à busca da justiça (Hossne, 2009).

Considera-se importante lembrar, nesse momento, da tese da equidade e da justiça distributiva defendida por Rawls (2000), na qual o pensador, embora admita a possibilidade da desigualdade econômica entre as pessoas, afirma que ela somente se justificaria se contribuísse para diminuir o distanciamento com aqueles que estão à margem da sociedade. Ou seja, para o autor permitese a desigualdade de renda a título de incentivo, desde que esses incentivos sejam necessários para melhorar a vida dos mais vulneráveis.

A Declaração universal dos direitos humanos, por sua vez, estabelece, em seu artigo 25, inciso I, que todo indivíduo tem direito a um padrão de vida capaz de assegurar a si e a sua família saúde, bem-estar e alimentação (ONU, 1948). A Declaração universal sobre bioética e direitos humanos, em seu artigo $10^{\circ}$ estabelece que a igualdade fundamental de todos os indivíduos em dignidade e em direitos deve ser respeitada para que eles sejam tratados de forma igual e justa (ONU, 2005).

A Declaração universal sobre bioética e direitos humanos defende ainda que a equidade e a responsabilidade social são valores que estão diretamente relacionados com o direito humano à alimentação adequada. E a justiça e igualdade, por sua vez, garantem o acesso universal à alimentação adequada sem qualquer forma de discriminação (Brasil, 2006; ONU, 2005). 
Se o Estado quer combater as causas estruturais da pobreza, garantindo o direito à alimentação, de estar livre da fome e da má nutrição, com o auxílio das políticas públicas, deverá potencializar a segurança alimentar e nutricional (Goulart, 2008).

No entanto, o provimento das liberdades das pessoas, seja das mais substantivas às mais complexas, deve ser um comprometimento social e não apenas um dever do Estado, necessitando também ser preconizado por outras instituições e organizações políticas e sociais de vários tipos, assim como pela mídia e os demais veículos de comunicação e entendimento público (ONU, 1948).

Nas diretrizes da Política nacional de alimentação e nutrição (Brasil, 2013), encontra-se indicado que prover a prática alimentar preservando os aspectos biológicos, sociais, ambientais, econômicos e culturais, respeitando gênero, raça e etnia, baseando-se em práticas sustentáveis para garantir alimentos em quantidade e qualidade (livre de contaminantes) a todos os indivíduos (Goulart, 2008), de modo a proteger o indivíduo de todo e qualquer dano à saúde e à vida, é uma obrigação do Estado.

O Direito humano à alimentação adequada, por sua vez, depende muito mais do que o acesso e a disponibilidade de alimentos saudáveis. A esse direito estão associados o estado de saúde das pessoas, a prestação de cuidados especiais a grupos humanos sociais e biologicamente vulneráveis, a construção da capacidade de todo ser humano de alimentar e nutrir a si próprio e à sua família, com dignidade, a partir do seu trabalho no campo ou na cidade. Esta compreensão mostra a indivisibilidade e a vinculação entre o direito humano à alimentação adequada, com a nutrição e o direito humano à saúde, com o comprometimento com as próximas gerações (Valente, 2003).

As famílias que vivem em vulnerabilidade estão expostas a vários tipos de riscos e não possuem capacidade de superar os desafios que aparecem no caminho (Janczura, 2012). Aqui tratamos as condições de vulnerabilidade não somente no âmbito de saúde ou de autonomia, mas como uma questão de direitos humanos, que por sua vez, também é apresentada com o objetivo de vinculá-la às suas raízes sociais mais profundas, estimulando e potencializando a mobilização das pessoas para a transformação destas condições indignas, articulando iniciativas governamentais e não governamentais em políticas públicas salvaguardando o DHAA, a SAN e os princípios estabelecidos pela bioética.

Caparrós (2016) nos questiona sobre quantos de nós, que temos acesso a informações sobre a fome, de fato sabemos o que é fome. Traz em seu livro A Fome a mitigação da especulação financeira e o uso do alimento como barreiras entre a vida e a morte de milhares de pessoas por dia, critério este estabelecido por dominadores do mercado capital. "Seria a fome um produto inevitável de nossa ordem mundial" (...) "A fome mata de forma silenciosa todos os anos três milhões de crianças, mais de oito mil por dia, mais de trezentas por hora, mais de cinco por minuto" (p.14). 
A fome no Brasil, descrita por Freitas (2007), é um produto de inúmeros significados visível pela desigualdade social e se concentra em pessoas que, desde a mais tenra idade, têm incertezas da sobrevivência cotidiana, e só é compreensível para quem a vivencia. Descrita como uma perversão social, a fome revela a dominação política e econômica como fatores da exclusão da equidade a todos os seres humanos.

A desumanização do acesso ao alimento coloca o sistema alimentar vigente como representante de uma das consequências da crise estrutural do capitalismo, em que a concentração de riquezas e mercadorias nas mãos de poucos, define o destino de muitos.

Se a atual produção mundial de alimentos já é suficiente para atender às necessidades de todos os habitantes do planeta, por que a erradicação da fome não se torna possível (Rosaneli, Ribeiro, Assis, Silva et al., 2015)? O compromisso de todos os governos nacionais deveria ser a meta indeclinável para permitir as capacidades e liberdades em defesa da vida perante a fome.

Entender como a alimentação está do minada pela lógica privada do capital e como o alimento virou mercadoria, explica o cenário atual de desigualdades econômicas e sociais que a fome e a pobreza acompanham no seu cotidiano (Machado, Oliveira, Mendes, 2016).

Com foco no aumento da disponibilidade alimentar, tem se defendido um sistema de produção, distribuição e consumo desigual, injusto e inconsequente à saúde dos indivíduos, fazendo ainda assim, permanecer a fome no mundo e a violação de direitos humanos.

Temos que tomar consciência de que as regras de mercado ditam questões relacionadas à agricultura e alimentação, e que aspectos morais e éticos para esta e as futuras gerações são primordialmente estabelecidos nestes cenários, que comprometem também a sustentabilidade do planeta. Para 2030 é esperado que a população mundial alcance acima de 8 bilhões de pessoas, e que $90 \%$ delas vivam em regiões em desenvolvimento. Desta forma, o compromisso ético com a produção de alimentos suficiente para todos será uma decisão destinada ao mercado (Esquinas, 2009).

De forma progressiva, saímos de um sistema diversificado e com raízes na riqueza dos solos para os amplos sistemas de produção agroalimentar montados por corporações transnacionais. Atualmente, praticamente em todo o mundo, a base da alimentação provém de um sistema de produção e distribuição em escala planetária, cabendo à indústria alimentícia o papel de definir o que, e como, as pessoas irão se nutrir.

O desperdício de alimentos é considerado o responsável pela fome no mundo. Certamente, o impacto deste desperdício alimentar pode ser sentido em vários níveis. Mas a indigesta má distribuição de alimentos contribui para a manutenção perversa da desigualdade orgânica da nossa caminhada enquanto humanidade. O desperdício é fatal, é diário, e é de todos.

Neste contexto, as desigualdades distributivas podem ser minimizadas jun- 
tamente com a promoção de justiça distributiva através da participação equitativa nas oportunidades globais, pois a exclusão desse tipo de participação também é uma fonte promotora de privação; grande parte dos conflitos gerados por privações surgem de inclusões inadequadas, bem como de circunstâncias desfavoráveis de participação (Sen, Kliksberg, 2010).

Contra o desperdício de alimentos, parcerias internacionais anunciaram o lançamento do primeiro padrão global para medir o problema da perda de alimentos no mundo, abrangente de definições e requisitos de comunicação para que empresas consigam medir, relatar e gerenciar de forma consistente e confiável a perda e o desperdício de alimentos. Este plano deverá ajudar a entender a trajetória do desperdício, bem como ajudar a definir uma linha de base para a ação contra o problema (FLW, 2016). Ingenuamente não podemos acreditar que apenas medir e planejar bastariam para acabar com um problema que perpetua pela história da humanidade.

O constrangimento e violação do direito à alimentação na fase contemporânea do capitalismo no Brasil (Machado, Oliveira, Mendes, 2016) atingem as políticas de liberalização e desregulamentação que garantem acesso das indústrias alimentícias transnacionais e passam a ser dominador e doutrinador, utilizando-se das mais diversas estratégias para criar novas necessidades de consumo, não acabando com a fome, e criando a fome de outros alimentos estabelecidos pelo mercado. As consequências desta fome de desejos interrompe o acesso aos alimentos saudáveis para o consumo de alimentos ultraprocessados em larga escala, por todos os tipos de consumidores, colocando a saúde pública em alerta constante, pelo aumento vertiginoso das doenças associadas ao novo padrão de consumo alimentar estabelecido.

A revolução tecnológica e industrial prometeu revolucionar o acesso de comida a todos, assegurando que isso significaria melhor qualidade e quantidade. Porém, não é só por meio da falta de comida que o perverso sistema alimentar mata. Ele nos oferece, de forma articulada aos interesses econômicos, grande quantidade de produtos industrializados que chamamos de comida. Este modelo mata jovens vítimas do consumo alimentar numa proporção cada vez maior, por agravos relacionados ao excesso de peso, à hipertensão, ao diabetes e a outras doenças cardiovasculares. Neste cenário, a falta de autonomia impera, pois as empresas transnacionais desenham as escolhas alimentares para a humanidade. Aspectos morais e éticos para esta e futuras gerações devem ser primordialmente estabelecidos no sistema alimentar, que compromete também a sustentabilidade no planeta, não acabando com a fome, e criando a fome de outros alimentos, aqueles estabelecidos pelo mercado.

Libertar a humanidade da fome e da má nutrição é uma obrigação moral. 0 mundo tem sem dúvidas uma capacidade produtiva que permite obter quantidades suficientes de alimentos nutritivos para todos, mas as oportunidades desiguais colocam a condição humana em fragilidade constante (Rosaneli, Ribeiro, Assis, Silva et al., 2015).

Ao longo de 10 mil anos a população humana tem procurado alternativas 
para acentuar a produção agrícola (FAO, 2004), mas a intensificação de meios tecnológicos para obter este fim, de aumentar a quantidade de alimentos, estabelece a necessidade de diálogo sobre as dimensões éticas do aumento da produção não sustentável, que compromete a saúde da Terra, e não garante o direito humano fundamental de acesso ao alimento aos mais necessitados para matar a fome, e respeitar a vida.

Os avanços tecnológicos no sistema alimentar podem ser irreversíveis de impacto no planeta. O modelo utilitarista e suas consequências na fome constante, já descrita e não resolvida, são estabelecidas por políticas que violam direitos e impossibilitam a justiça e a equidade.

Do ponto de vista de uma ética baseada nos direitos, é necessário considerar que tanto a fome, como o desperdício de alimentos, desprotegem o indivíduo de suas capacidades humanas, violando sua dignidade.

\section{Desenvolvimento, liberdade e o combate à fome}

O desperdício de alimentos é um desperdício de capacidades humanas. Ziegler (2012) sublinha que cada ser humano que hoje morre de fome é vitima de um sistema homicida desolador.

Desta forma, estamos imersos em um mundo marcado por privações, destituições e opressões fora do que se poderia ter imaginado para este período, em que a persistência da pobreza, a não satisfação das necessidades essenciais, a violação de liberdade políticas elementares, bem como de liberdades formais básicas, aliadas às graves ameaças ao meio ambiente e à não sustentabilidade econômica e social, agravam ainda mais a situação do desenvolvimento da humanidade.

As injustiças predominantes em nossa sociedade estão ligadas a um contínuo processo de omissões. Neste enquadramento destacam-se as deficiências institucionais e de políticas globais, as quais deveriam zelar por um comércio justo, práticas de saúde, educação, disseminação de avanços tecnológicos e cuidados com o meio ambiente (FAO, 2014).

Dentro do contexto da fome, estas injustiças também aparecem e se maximizam ainda mais quando se associam a outras condições sociais marcadas pela privação. Entre as principais fontes de privação comprometedoras das capacidades básicas humanas está a pobreza, a qual deve ser compreendida como algo que envolve muito mais do que apenas insuficiência de renda (Sen, 1999).

Na condição da pobreza, a pessoa humana não pode exercer a sua vontade racional e é forçada a aguentar todas as privações, desperdiçando sua capacidade humana numa injustiça ética, tornando-se vulnerável às condições 
mínimas essenciais para tratar todas as pessoas com o respeito moral que Ihes é devido (Sen, 1999).

A pobreza de renda e a pobreza de capacidades estão intimamente ligadas. Todavia, à atenuação da pobreza de renda não pode ser o foco principal das políticas de erradicação da pobreza; outros fatores precisam ser estimados, levando em voga que ao se propiciar oportunidades para que as pessoas exercitem suas capacidades, principalmente a de gerir suas vidas, se nutre os potenciais das mesmas e automaticamente se estabelece um processo onde elas se tornariam mais produtivas. Ou seja, a elevação das capacidades humanas acarreta condições para se aumentar renda, auxiliando ainda para que as privações humanas se tornem mais raras e escassas (Sen, 2011).

O fenômeno da globalização pode servir para alavancar ou obstruir a obrigação moral do acesso ao desenvolvimento e aos diretos mais básicos, onde um desenvolvimento para ser caracterizado como justo ou bom deve assegurar o exercício e o acesso das capacidades básicas a todos (Pinheiro, 2012).

O desenvolvimento humano é um desafio e deve ser promovido junto com a obtenção do aumento das capacidades de realização nos diferentes tipos de vida que se pode obter, devendo priorizar o não aparecimento de circunstâncias que tornam o ser humano escravo de sua condição social (Sen, 2011).

O desenvolvimento apresenta como imposição a eliminação de fontes geradoras de privação de liberdade, tais como pobreza, tirania, carência de oportunidades econômicas, não favorecimento social, negligência de serviços públicos e uma não mediação excessiva de um Estado repressivo. Estas fontes de privação de liberdade são causadoras de injustiças, disparidades e iniquidades, e para combatê-las se faz necessário promover a obtenção de diversos tipos de liberdades (Brasil, 2013; Sen, 2011).

Zelar pela garantia ao acesso de liberdade é relevante, visto que ela contribui para que as pessoas tenham capacidade de atingir a vida que desejam, tornando-se agentes de sua própria biografia. Com efeito, a liberdade é o exercitar da autodeterminação, autonomia e do poder. É devido a isto que se deve utilizar a liberdade como uma aliada no processo de desenvolvimento na busca da extinção de desigualdades, privações e injustiças persistentes (Brasil, 2013; Pinheiro, 2012; Sen, 2011).

A vasta gama de liberdades defendidas por Sen (1999) estão ligadas às essências descritivas e prescritivas, tais como leis, regras e normativas, onde se referencia diversos estados e objetos incluindo a liberdade de se adquirir bens e serviços, de ser saudável, liberdade de não estar sujeito à morte prematura, de estar bem nutrido, de não passar fome, entre outros.

Dentre as liberdades substantivas que devem ser fomentadas pelo desenvolvimento está a expansão de serviços promotores de saúde, educação, redução de taxas de mortalidade, seguridade social, aumento da renda, independência econômica feminina, oportunidade de planejamento familiar, e o acesso a uma alimentação adequada e segura. E entre as liberdades mais relevantes 
estão aquelas que tornam as pessoas agentes de sua própria vida, de modo a reconhecer-se como cidadão pleno e ativo, responsável por seu bem estar e pela forma como usa suas capacidades, consequentemente, seu potencial de levar a vida que se valoriza (Brasil, 2013).

Para promover o desenvolvimento em forma de liberdade é necessário utilizar de abordagens múltiplas de amplo alcance, maximizando o desenvolvimento de oportunidades sociais, provendo as necessidades básicas das pessoas, a fim de que se reduza ao máximo todo e qualquer processo de privação das liberdades substantivas das mesmas (Sen, 2011; Sen, Kliksberg, 2010).

Para saber se uma sociedade está apresentando progresso em seu desenvolvimento, é necessário verificar o grau de liberdade e as atuais condições das pessoas desenvolverem suas potencialidades, de forma maximizada o quanto for possível, e é justamente por isso, que combater a fome é essencial, pois ela limita o potencial de desenvolvimento que as vidas humanas devem atingir (ONU, 2016).

\section{Considerações finais}

O flagelo da fome não representa unicamente um problema técnico e político, pois os números mostram que a produção de alimentos é superior ao crescimento populacional, mas, sobretudo, um problema ético e bioético, pois a má distribuição de alimentos gera injustiça e viola o direito humano à alimentação adequada.

A fome é uma violência e um insulto que desumaniza e destrói o corpo. Nesse sentido, a falta de sensibilidade para com os nossos semelhantes vitimados pela fome faz da indiferença, e a falta de solidariedade, uma realidade ainda mais perversa. Ao privilegiar o indivíduo, e não a coletividade, a apropriação privada e não a coparticipação solidária, a nossa sociedade promove uma ética egoísta e excludente, e tenta justificar moralmente tal realidade.

O domínio do poder econômico sobre o poder político, tornando-o refém, faz com que os ganhos não sejam compartilhados em benefícios de todos, o que institui ao poder político distância do bem comum. Somente com uma reviravolta nesse cenário, com uma inversão de valores, com uma economia submetida à política, e esta orientada por uma ética que promova a solidariedade, a compaixão e a justiça, será possível reduzir ou eliminar a fome no mundo e assegurar a dignidade a toda a humanidade.

Por mais utópica que possa parecer a afirmação acima, sabemos que uma das contribuições das utopias é fazer-nos caminhar; e nessa caminhada é urgente despertar-nos e ver se somos capazes com a quantidade de alimentos produzidos na atualidade de sanarmos o problema da fome e da violação dos direitos humanos. Se não o fizermos, nos desumanizaremos, pois o ato de alimentar vai muito além de nutrir o corpo; com ele conferimos dignidade, humanidade e respeito às pessoas. Somente com uma "política da vida" para superar 
a atual "política da morte" será possível alcançarmos tal objetivo. Esta "política da vida" terá que se orientar por princípios éticos que assegurem, acima de tudo, uma dignidade humana na vida concreta, pois o indivíduo que passa fome exige a prática do princípio da dignidade humana e não pode mais esperar.

\section{Referências}

1. ABRANDH. Ação Brasileira pela Nutrição e Direitos Humanos. Direito Humano à Alimentação Adequada no contexto da Segurança Alimentar e Nutricional. Brasília, 2010.

2. Albuquerque MFM. A segurança alimentar e nutricional e o uso da abordagem de direitos humanos no desenho das políticas públicas para combater a fome e a pobreza. Revista de Nutrição 2009; 22(6): 895-903.

3. Belik W, Cunha ARAA, Costa LA. Crise dos alimentos e estratégias para a redução do desperdício no contexto de uma política de segurança alimentar e nutricional no Brasil. Revista de planejamento e políticas públicas 2012; 38: 107-132.

4. BRASIL. Decreto no 59, de 6 julho de 1992. Pacto Internacional sobre direitos econômicos, sociais e culturais. Acessível em: http://www.planalto.gov.br/ccivil_03/decreto/1990-1994/d0591.htm

5. BRASIL. Lei no 11.346, de 15 de setembro de 2006. CONSEA. Brasília, 2006. Acessível em: https://www.planalto.gov.br/ccivil_03/_Ato2004-2006/2006/Lei/L11346.htm.

6. BRASIL. Ministério da Saúde. Política Nacional de Alimentação e Nutrição (2012). Brasília, 2013.

7. BRASIL. Plano Nacional de Segurança Alimentar e Nutricional revisado-2012/2015. Câmara Interministerial de Segurança Alimentar e Nutricional. Brasília, 2014.

8. Caparrós M. A fome. Rio de Janeiro: Bertrand Brasil, 2016.

9. de Freitas MCS. Fome: ameaça a vida e interrompe sonhos. Cadernos IHU em formação 2007; 23:18-19.

10. Demo P. Metodologia do conhecimento científico. São Paulo: Atlas; 2000.

11. Esquinas JTA. Biodiversidad agrícola, biotecnología y bioética en la lucha contra el hambre y la pobreza. Revista Latinoamerica de Bioetica 2009; 9(1):102-113.

12. FAO. La ética de la intensificación sostenible de la agricultura. Estudio FAO - Cuestiones de ética. Roma, 2004.

13. FAO. Organização das Nações Unidas para a Alimentação e Agricultura. O estado da Segurança Alimentar e Nutricional no Brasil. Brasília, 2014. Acessível em: https://www.fao. org.br/download/SOFI_p.pdf.

14. FLW. FLW protocol standard. Acessível em: http://flwprotocol.org/.

15. Goulart RMM. Desperdício de Alimentos: Um problema de saúde pública. Revista Integração 2008; 54: 285-288.

16. Hossne WS. Dos referenciais da bioética - a Equidade. Revista Bioethicos 2009; 3(2): 211-216.

17. IHU. Desperdício e perda de alimentos. Revista Instituto Humanitas Unisinos 2014; 14(452):5-47. 
18. Janczura R. Risco ou vulnerabilidade social? Textos e conceitos 2012; 11(2): 301-308.

19. Machado P, Oliveira N, Mendes A. O indigesto Sistema do Alimento Mercadoria. Saúde Sociedade 2016; 25(2): 505-515.

20. ONU. Organização das Nações Unidas - Brasil. 2016. Acessível em: https://nacoesuni-das.org/onu-anuncia-o-lancamento-do-primeiro-padrao-global-para-medir-perda-edesperdicio-de-alimentos.

21. ONU. Organização das Nações Unidas para a Educação, a Ciência e a Cultura. Declaração Universal sobre Bioética e Direitos Humanos. Paris: Unesco, 2005.

22. ONU. Organização das Nações Unidas. Declaração universal dos direitos humanos. 1948.

23. Pessini L, Garrafa V. Bioética: Poder e Injustiça. São Paulo: São Camilo, 2003.

24. Pinheiro MMS. As liberdades humanas como bases do desenvolvimento: uma análise conceitual da abordagem das capacidades humanas de Amartya Sen. Rio de Janeiro: Instituto de Pesquisa Econômica Aplicada, 2012.

25. Rawls J. O liberalismo Político. São Paulo: Ática, 2000.

26. Rosaneli CF, Ribeiro ALC, de Assis L, da Silva TM, de Siqueira JE. A fragilidade humana diante da pobreza e da fome. Revista Bioética 2015; 23(1): 89-97.

27. Santos GC, Arcoverde ACB. Pobreza, conceitos, mensuração e enfrentamento no Brasil. In: Anais da Jornada Internacional de Políticas Pública. São Luís, Pernambuco, Brasil; 2011.

28. Schramm FR. Bioética da Proteção: ferramenta válida para enfrentar problemas morais na era da globalização. Revista Bioêtica 2008; 16(1): 11-23.

29. Sen A, Kliksberg B. As pessoas em primeiro lugar: A ética do desenvolvimento e os problemas do mundo globalizado. São Paulo: Companhia das Letras, 2010.

30. Sen A. Pobreza e Fomes: um ensaio sobre direitos e privações. Lisboa: Terramar, 1999.

31. Sen A. A ideia de justiça. São Paulo: Companhia das Letras, 2011.

32. Soares AG. Desperdício de Alimentos no Brasil: um desafio político e social a ser venci- do. Embrapa Agroindústria de Alimentos, Rio de Janeiro, 2014. Acessível em: http://www. ctaa. embrapa.br/upload/publicacao/art-182.pdf.

33. Valente FLS. Fome, desnutrição e cidadania: inclusão social e direitos humanos. Revista Saúde e Sociedade 2003; 12(1): 51-60.

34. Vicino C. Fome no Brasil, 14 milhões de pessoas passam fome. Acessível em: http:// www.senado.gov.br/senado/portaldoservidor/jornal/jornal66/utilidade_publica_fome. aspx\#

35. Ziegler J. Destruição em Massa: geopolítica da fome. São Paulo: Cortez, 2012.

Recebido em: 22/09/2016. Aprovado em: 06/11/2016. 